\title{
Oceanic Influences on Recent Continental Warming
}

\author{
GiLBert P. COMPO \\ Prashant D. SARDESHMUKH \\ Climate Diagnostics Center, \\ Cooperative Institute for Research in Environmental Sciences, \\ University of Colorado, and \\ Physical Sciences Division, Earth System Research Laboratory, \\ National Oceanic and Atmospheric Administration \\ 325 Broadway R/PSD1 \\ Boulder CO 80305-3328 \\ compo@colorado.edu \\ (303) 497-6115 \\ (303) 497-6449
}

\section{Citation:}

Compo, G.P., and P.D. Sardeshmukh, 2009: Oceanic influences on recent continental warming. Climate Dynamics, 32, 333-342 doi: 10.1007/s00382-008-0448-9.

This article is published by Springer-Verlag. This author-created version is distributed courtesy of Springer-Verlag. The original publication is available from www.springerlink.com at http://www.springerlink.com/content/au9x401201105273/fulltext.pdf 


\begin{abstract}
Evidence is presented that the recent worldwide land warming has occurred largely in response to a worldwide warming of the oceans rather than as a direct response to increasing greenhouse gases (GHGs) over land. Atmospheric model simulations of the last half-century with prescribed observed ocean temperature changes, but without prescribed GHG changes, account for most of the land warming. The oceanic influence has occurred through hydrodynamic-radiative teleconnections, primarily by moistening and warming the air over land and increasing the downward longwave radiation at the surface. The oceans may themselves have warmed from a combination of natural and anthropogenic influences.
\end{abstract}




\section{Introduction}

The general warming trend of near-surface temperatures since the late $19^{\text {th }}$ century appears to have intensified since the mid-1970s (Stott et al. 2006; Knutson et al. 2006), and emerged unambiguously from a background of simulated natural climate variability after about 1990 (Stott et al. 2006). Global climate models with prescribed variations of greenhouse gases (GHGs), aerosols, and solar forcing are now proving successful at capturing the global mean as well as some regional aspects of these temperature variations (Stott et al. 2006; Knutson et al. 2006; Hegerl et al. 2007).

Figure 1a illustrates the global extent of the recent observed warming as the 1991-2006 average minus the 1961-1990 average. The near-ubiquity of the warming, especially over the continents, is striking. To what degree is this directly attributable to local GHG increases? For the planet as a whole, there is little doubt that the inhibition of outgoing longwave radiation by such increases leads to radiative heating of the surface (i.e. the greenhouse effect), with the warming subsequently modified by water vapor and other feedbacks (Houghton et al. 2001). But does this also apply locally to each region in Fig. 1a? The primary conclusion of our study is that it does not. Indeed we find compelling evidence from several atmospheric general circulation model simulations without prescribed GHG, aerosol, and solar forcing variations (Table 1) that the continental warming in Fig. 1a is largely a response to the warming of the oceans rather than directly due to GHG increases over the continents (Table 2).

\section{Observational and atmospheric model data}

The four most recently updated observed air and sea surface temperature (SST) datasets were combined in an unweighted average to create Fig. 1a and Table 2. Although these datasets [HadCRUT3v (Brohan et al. 2006), HadISST1 (Rayner et al. 2003), National Aeronautics and Space Administration (NASA) GISTEMP Combined at $250 \mathrm{~km}$ resolution (Hansen et al. 2001), and National Oceanic and Atmospheric Administration (NOAA) Merged Land, Air, and SST (MLASST) (Smith and Reynolds 2005)] are based on overlapping sources and methods, they show some differences in their estimates of temperature variability. We therefore used an unweighted blend to estimate the observed temperature variations.

Our study also makes use of several AGCM simulations generated at modeling centers in the United States (Table 1). AGCM integrations with prescribed observed SSTs are a standard method of investigating atmospheric variability on interannual (e.g., Lau 1997, Sardeshmukh et al. 2000, Shukla et 
al. 2000), decadal (e.g., Hoerling and Kumar 2003; Seager et al. 2005), and multi-decadal time scales (e.g., Rodwell et al. 1999; Schneider et al. 2003; Sexton et al. 2003; Hurrell et al. 2004; Deser and Phillips 2008). This experimental design forms the basis for the several hundred multi-decadal AGCM integrations with prescribed SSTs that have been performed as part of the CLIVAR International "Climate of the Twentieth Century" Project (Folland et al. 2002). Our study uses two sets of ensemble integrations with specified observed SSTs and different atmospheric initial conditions available for the

period 1961-2006, one generated at the International Research Institute (IRI) using the European/ECHAM4.5 spectral model, and the other at NASA using the NASA NSIPP gridpoint model at two different horizontal resolutions. The NSIPP high-resolution model also had specified time-varying sea ice (Table 1). Schubert et al. (2004b) found little difference between the NSIPP model's climatology or variability at the two resolutions; we therefore combined those runs to reduce sampling errors. An additional set of 8 NASA model simulations at the lower horizontal resolution, with both prescribed SST and $\mathrm{CO}_{2}$ variations was also available. The $\mathrm{CO}_{2}$ variations were as in Johns et al. (2003).

To complement these simulations, we used 54 additional model simulations extending only up to 2000 . Each was generated using prescribed observed SSTs and different atmospheric initial conditions (Table 1). An additional 10-member set of NCAR/CAM3 model simulations with prescribed radiative forcings was also available, and is referred to here as the NCAR/CAM3 Intergovernmental Panel on Climate Change forcings (IPCC) ensemble. These simulations had the same specified time-varying boundary conditions as the NCAR/CAM3 integrations, but also specified anthropogenic and natural radiative forcings as in Meehl et al. (2006). The forcings included time-varying solar irradiance and volcanic aerosols, anthropogenic sulfate aerosols, tropospheric and stratospheric ozone, well-mixed $\mathrm{GHGs}\left(\mathrm{CO}_{2}\right.$, $\mathrm{CH}_{4}, \mathrm{~N}_{2} \mathrm{O}$ ), halocarbons, and black carbon aerosols.

\section{Oceanic influence on recent land warming}

Figure $1 \mathrm{~b}$ shows the mean land warming in the 24 simulations of the European/ECHAM4.5 model. It not only captures the essence of the continental warming in Fig. 1a, but also some aspects of the spatial variation (Table 2). The reproducibility of the result is demonstrated in Fig. 1c, derived from a similar set of 23 simulations using the NASA/NSIPP model. This model also captures the magnitude and overall pattern of the observed continental warming (Table 2). The details of the spatial patterns comparing Figs. $1 \mathrm{~b}$ and 1c with Fig. 1a are, however, not well represented, with anomaly pattern correlations (after the global land mean warming is removed) of only 0.03 and 0.06 , respectively. 
We also examined the warming in these and in other ensemble simulations generated using four other models for a shorter period (1991-2000). The results are generally consistent with those for the 19912006 period (Table 2). While all models show a small negative bias in their mean difference between the simulated and observed land warming, none is significantly different from zero at the $5 \%$ level (Table 2 ). More powerfully, for each ensemble-mean simulation Table 2 also shows the percentage of land area in which the simulated warming is larger than the observed warming. These percentages cannot be statistically distinguished from the 50\% expected for a binomial distribution if the number of independent points (degrees of freedom) of the temperature observations is less than 58. Current estimates of the degrees of freedom in global fields of decadal temperature averages range from 3 to 8 (Jones et al. 1997). The models also replicate the larger observed land-averaged warmth of $1991-2006\left(+0.48^{\circ} \mathrm{C}\right)$ than that of $1991-2000\left(+0.38^{\circ} \mathrm{C}\right)$ relative to the 1961-1990 reference period. Additionally, the models reproduce the observation that the land-averaged warming in both periods is approximately double the ocean-averaged warming of $+0.23^{\circ} \mathrm{C}$ in $1991-2006$ and $+0.19^{\circ} \mathrm{C}$ in $1991-2000$ (Sutton et al. 2007). Thus, together with Fig. 1, these results suggest that the observed continental warming in both 1991-2006 and 1991-2000 relative to 1961-1990 was consistent with oceanic forcing.

Oceanic forcing of global atmospheric variations on interannual to decadal scales (Horel and Wallace 1981; Deser and Phillips 2006) is often associated with planetary Rossby waves dispersing from a region of deep atmospheric convection and outflow at the upper tropospheric jet level (Sardeshmukh and Hoskins 1988; Ting and Sardeshmukh 1993). It is also often associated with changes in the Hadley and Walker circulations, with a tendency to warm the atmosphere in their descending branches. These dynamical mechanisms, however, inevitably induce some spatial variation in the response. In view of this, the near-uniformity of the warming in Fig. 1 is striking. A different mechanism must be dominant. Since we suspect the primary greenhouse gas - water vapor - to play a significant role in the temperature response to radiative perturbations (Schneider et al. 1999; Held and Soden 2000), we examine its behavior in the NASA/NSIPP model simulations for which we have a complete set of archived quantities.

Figure 2a shows the mean fractional change of $300 \mathrm{hPa}$ humidity in the NASA/NSIPP simulations. Its spatial distribution is extremely uniform, and correlates with the surface temperature warming pattern at 0.82. Associated with the altered humidity is altered tropospheric temperature (Fig. 2b). The change in $300 \mathrm{hPa}$ air temperature correlates with the surface temperature warming pattern at 0.87 . The humidity 
and temperature changes at other tropospheric levels down to $850 \mathrm{hPa}$ show similar correlations. These changes lead to increased downward surface longwave radiation at all continental locations (Fig. 3a). The spatial patterns of this downward longwave flux and surface temperature change are correlated at 0.93 , which suggests that the change in the surface longwave flux is a dominant driver of the surface warming.

Another contributor to the continental surface warming is enhanced tropospheric descent associated with the atmospheric circulation response to the warm SSTs in Fig. 1a. The areas of simulated anomalous ascent and descent in the mid-troposphere (Fig. 2c) clearly reflect the wavy structures expected as part of the circulation response. Over the tropical Indian and western Pacific oceans, the pattern of anomalous ascent and descent corresponds directly to that of increased and reduced model precipitation, and thus to a pattern of altered diabatic forcing of the global atmospheric circulation. As part of the circulation response, descent is enhanced in many continental regions, both in the Tropics and at higher latitudes. Such regions would be expected to have reduced cloud cover (Bony et al. 2004) consistent with the regions of decreased $300 \mathrm{hPa}$ relative humidity (Fig. 2d), and therefore more shortwave radiation reaching the surface. Comparing the regions of enhanced continental descent (Fig. 2c) and decreased relative humidity (Fig. 2d) with regions of enhanced surface shortwave absorption (Fig. 3b) indeed reveals a close association between them. Over the continents, the patterns of altered vertical motion and $300 \mathrm{hPa}$ relative humidity correlate with that of the shortwave absorption at 0.71 and -0.61 , respectively. The pattern correlation of the shortwave absoption and surface temperature change is 0.50 , which, although not very large, is statistically significant at the $10 \%$ level assuming 8 degrees of freedom. Enhanced surface absorption of shortwave radiation is thus also an important contributor to the warming in some regions.

The surface warming is offset by cooling from the altered flux of upwelling longwave radiation (Fig. 3c) and the turbulent fluxes of sensible and latent heat (Fig. 3d). The pattern of the change in upwelling longwave radiation correlates with the pattern of surface warming (Fig. 1c) at -0.97, while the pattern of the change of the turbulent fluxes has a correlation of only -0.47 , which is marginally significant (at the $12 \%$ level assuming 8 degrees of freedom).

Changes in horizontal temperature advection in the 1000 to $850 \mathrm{hPa}$ layer also affect the near surface temperature, and in a spatially-varying manner consistent with the expected wavy circulation response (Fig. 4). These changes act to counter the near-surface warming in most regions, but contribute to the 
warming in a few areas such as east Asia. The pattern correlation of the advective tendency change with the surface temperature change (Fig. 1c) is nearly 0 over the continents.

Overall, the results suggest that the dominant mechanism for the land warming in these simulations is enhanced downwelling longwave radiation. This enhancement is associated with increases of both uppertropospheric humidity and temperature over land, which themselves can occur in these simulations only through oceanic forcing, by experimental design.

The connection between specific humidity, relative humidity, and temperature through the ClausiusClapeyron equation raises the issue of whether the moistening and warming in Fig. 2 simply reflects the well-known feedback of water vapor on temperature under a constant relative humidity scenario (e.g., Held and Soden (2000)). We find that it does not. First of all, relative humidity does not remain constant in these simulations, as shown in Fig. 2d. The increase of specific humidity in some mid-latitude regions is in fact nearly double what one would expect if relative humidity were to remain constant, and the tropics-wide increase of specific humidity (Fig 2a) occurs despite a decrease of relative humidity (Fig. 2d). Schneider et al. (1999) isolated the effects of variable water vapor, variable clouds, and constant relative humidity on the surface temperature response to a doubling of atmospheric $\mathrm{CO}_{2}$. Held and Soden (2000) analyzed an idealized surface temperature response to a doubling of atmospheric $\mathrm{CO}_{2}$ with and without water-vapor feedback, assuming constant relative humidity. The two studies suggest that the water-vapor feedback with constant relative humidity doubles the surface temperature response to a radiative perturbation. They also suggest that interactive water vapor and clouds further increase the response by $\sim 25 \%-50 \%$. In the experiments here, the initial radiative perturbation leading to a warming of the upper troposphere has to result from ocean-forced changes of circulation or water vapor transport, suggesting an even greater importance of water vapor changes than expected from the two $\mathrm{CO}_{2}$ sensitivity studies. Additional experiments will be needed to isolate these various hydrological, dynamical, and radiative effects giving rise to a "hydrodynamic-radiative" teleconnection from the oceans to the land.

\section{Direct effect of GHGs, aerosols, and solar activity}

While the ocean-forced changes account for the major features of the observed continental warming in Fig. 1, some discrepancies remain, especially over eastern central Asia and western North America. An obvious possible explanation is the neglect of the direct radiative effects (as opposed to the indirect effects through oceanic warming) of the observed time-varying GHGs and aerosols in the simulations 
(Fig. 1b, 1c). How large are these direct effects? Fig. 5 provides one possible answer. In it, we compare the lower-resolution NASA/NSIPP simulations using only prescribed observed SSTs with simulations that also include the direct effects of prescribed time-varying $\mathrm{CO}_{2}$ (Fig. 5a and 5c). Evidently, the direct effects of $\mathrm{CO}_{2}$ on continental warming, at least in this particular model, are much smaller than the oceanforced indirect effect. (This is not to say that the $\mathrm{CO}_{2}$ variations have no direct effect in these simulations; there is a significant cooling of the model's stratosphere, consistent with previous results (Sexton et al. 2003)).

We have also compared NCAR/CAM3 simulations of 1991-2000 with prescribed SST variations to simulations in which the time-varying natural and anthropogenic IPCC radiative forcings were also prescribed (Fig. 5b, 5d). These NCAR/CAM3 (IPCC) simulations have the best overall correspondence with the observed temperature change in pattern and magnitude for this period (Table 2), but the improvement is minor. Including the radiative forcings slightly reduces the error in the northern high latitudes and southeastern United States in Fig. 5b compared to observations (The observed 1991-2000 temperature difference from 1961-1990 is very similar to Fig. 1a, with a pattern correlation of 0.96). This suggests that the direct effects of the combined radiative forcings, and not just those of $\mathrm{CO}_{2}$, have contributed to the recent warming in these regions. Still, the fact that fully coupled climate models with observed anthropogenic and natural radiative forcings also have errors similar to ours in these regions in the recent period (Stott et al. 2006; Knutson et al. 2006) suggests that in the prescribed-SST simulations presented here neither the neglect of these forcings, nor that of ocean-atmosphere coupling, is a major cause of the model discrepancies in Fig. 1.

Given the substantial oceanic influence on land warming found here, it is relevant to consider to what extent our diagnostic method is justified, i.e., to what extent the oceanic influence on land warming can be diagnosed through prescribed-SST simulations. The success of many previous diagnostic studies of atmospheric variations through such simulations is encouraging in this regard, and is basically due to the fact that a substantial portion of the coupling effect is already implicit in the prescribed observed SSTs. To see what error can occur from not fully accounting for the coupling, consider the following set of linear anomaly equations for the coupled ocean-atmosphere system : 


$$
\begin{aligned}
& \frac{d \mathbf{y}}{d t}=\mathbf{L}_{y y} \mathbf{y}+\mathbf{L}_{y x} \mathbf{x}+\mathbf{B}_{y} \boldsymbol{\eta}_{y}+\mathbf{F}_{y} \\
& \frac{d \mathbf{x}}{d t}=\mathbf{L}_{x y} \mathbf{y}+\mathbf{L}_{x x} \mathbf{x}+\mathbf{B}_{x} \boldsymbol{\eta}_{x}+\mathbf{F}_{x}
\end{aligned}
$$

where $\mathbf{y}$ represents the complete atmospheric state vector and $\mathbf{x}$ represents the SST state vector. The matrices $\mathbf{L}_{\alpha \beta}$ represent interactions between and among the atmospheric and oceanic variables, and the vectors $\mathbf{B}_{\alpha} \eta_{\alpha}$ and $\mathbf{F}_{\alpha}$ represent the stochastic and radiative forcings, respectively, of those variables. On long time scales, the ensemble mean atmospheric anomaly is given approximately by

$$
\begin{aligned}
\langle\mathbf{y}\rangle & \approx-\mathbf{L}_{y y}{ }^{-1}\left\{\mathbf{L}_{y x}\langle\mathbf{x}\rangle+\mathbf{B}_{y}\left\langle\boldsymbol{\eta}_{y}\right\rangle+\mathbf{F}_{y}\right\} \\
& \approx-\left[\mathbf{L}_{y y}{ }^{-1} \mathbf{L}_{y x}\right]\langle\mathbf{x}\rangle-\mathbf{L}_{y y}{ }^{-1} \mathbf{F}_{y} \\
& \approx \mathbf{G}\langle\mathbf{x}\rangle-\mathbf{L}_{y y}{ }^{-1} \mathbf{F}_{y}
\end{aligned}
$$

where $\langle\bullet\rangle$ indicates an ensemble average. Note that the ensemble average of the stochastic forcing $\left\langle\boldsymbol{\eta}_{y}\right\rangle$ is zero.

What error is made by integrating the atmospheric model $\mathbf{y}$ with prescribed observed variations of $\mathbf{x}$ from the fully coupled system? The equation for the atmospheric evolution is now

$$
\frac{d \hat{\mathbf{y}}}{d t}=\mathbf{L}_{y y} \hat{\mathbf{y}}+\mathbf{L}_{y x} \mathbf{x}+\mathbf{B}_{y} \hat{\eta}_{y}+\mathbf{F}_{y} .
$$

The only difference between this equation and the atmospheric equation in the coupled system (1) is that the stochastic noise is different (although its statistics are the same). In general, the individual sample paths of $\hat{\mathbf{y}}$ will differ from those of $\mathbf{y}$ because the sample paths of the stochastic noise differ, i.e. $\hat{\eta}_{y} \neq \eta_{y}$. The question is whether the statistics of $\hat{\mathbf{y}}$ will also differ from those of $\mathbf{y}$, even though the amplitudes $\mathbf{B}_{y}$ of $\hat{\eta}_{y}$ and $\eta_{y}$ are the same. One can see that in general the variance and covariance statistics of $\hat{\mathbf{y}}$ will differ from those of $\mathbf{y}$ because on long timescales $\mathbf{x}$ and $\eta_{y}$ are correlated in the coupled system (1), but not in the prescribed-SST system (3) by prescription. However, the ensemble mean response $\langle\hat{\mathbf{y}}\rangle$ will still be the same, because just as in the coupled system (2), on long time scales, 


$$
\begin{aligned}
\langle\hat{\mathbf{y}}\rangle & \approx-\mathbf{L}_{y y}{ }^{-1}\left\{\mathbf{L}_{y x}\langle\mathbf{x}\rangle+\mathbf{B}_{y}\left\langle\hat{\boldsymbol{\eta}}_{y}\right\rangle+\mathbf{F}_{y}\right\} \\
& \approx-\left[\mathbf{L}_{y y}{ }^{-1} \mathbf{L}_{y x}\right]\langle\mathbf{x}\rangle-\mathbf{L}_{y y}{ }^{-1} \mathbf{F}_{y} \\
& \approx \mathbf{G}\langle\mathbf{x}\rangle-\mathbf{L}_{y y}{ }^{-1} \mathbf{F}_{y}
\end{aligned}
$$

since the ensemble mean of the stochastic forcing $\left\langle\hat{\eta}_{y}\right\rangle$ is again zero. Therefore, to the extent that the anomaly equations for the coupled system can be approximated as linear equations with stochastic and external forcings, one can expect the ensemble mean atmospheric responses to prescribed SSTs with and without additional radiative forcings to be consistent with those in the coupled system. There is substantial evidence that the coupled atmosphere-ocean system does behave linearly on interannual to decadal timescales in response to both radiative (Meehl et al. 2004; Cash et al. 2005; Knutson et al. 2006 and references therein; Deser and Phillips 2008) and stochastic (Penland and Sardeshmukh 1995; Thompson and Battisti 2001) forcings. The linearity of the responses to SST forcings (especially tropical SST forcing) has also been demonstrated (Barsugli and Sardeshmukh 2002; Schneider et al. 2003; Barsugli et al. 2006; Deser and Phillips 2008).

\section{Discussion and conclusions}

In summary, our results emphasize the significant role of remote oceanic influences, rather than the direct local effect of anthropogenic radiative forcings, in the recent continental warming. They suggest that the recent oceanic warming has caused the continents to warm through a different set of mechanisms than usually identified with the global impacts of SST changes. It has increased the humidity of the atmosphere, altered the atmospheric vertical motion and associated cloud fields, and perturbed the longwave and shortwave radiative fluxes at the continental surface. While continuous global measurements of most of these changes are not available through the 1961-2006 period, some humidity observations are available and do show upward trends over the continents. These include near-surface observations (Dai 2006) as well as satellite radiance measurements sensitive to upper tropospheric moisture (Soden et al. 2005).

Although not a focus of this study, the degree to which the oceans themselves have recently warmed due to increased GHG, other anthropogenic, natural solar and volcanic forcings, or internal multi-decadal climate variations is a matter of active investigation (Stott et al. 2006; Knutson et al. 2006; Pierce et al. 2006). Reliable assessments of these contributing factors depend critically on reliable estimations of 
natural climate variability, either from the observational record or from coupled climate model simulations without anthropogenic forcings. Several recent studies suggest that the observed SST variability may be misrepresented in the coupled models used in preparing the IPCC's Fourth Assessment Report, with substantial errors on interannual and decadal scales (e.g., Shukla et al. 2006, DelSole, 2006; Newman 2007; Newman et al. 2008). There is a hint of an underestimation of simulated decadal SST variability even in the published IPCC Report (Hegerl et al. 2007, FAQ9.2 Figure 1). Given these and other misrepresentations of natural oceanic variability on decadal scales (e.g., Zhang and McPhaden 2006), a role for natural causes of at least some of the recent oceanic warming should not be ruled out.

Regardless of whether or not the rapid recent oceanic warming has occurred largely from anthropogenic or natural influences, our study highlights its importance in accounting for the recent observed continental warming. Perhaps the most important conclusion to be drawn from our analysis is that the recent acceleration of global warming may not be occurring in quite the manner one might have imagined. The indirect and substantial role of the oceans in causing the recent continental warming emphasizes the need to generate reliable projections of ocean temperature changes over the next century, in order to generate more reliable projections of not just the global mean temperature and precipitation changes (Barsugli et al. 2006), but also regional climate changes. 
Acknowledgments. We thank the following colleagues and observational and modeling centers for providing data and model output: P. Brohan, P. Jones, the UK Met Office Hadley Center, and the University of East Anglia Climatic Research Unit for HadCRUT3v; N. Rayner and the UK Met Office Hadley Center for HadISST1.1; J. Hansen and NASA GISS for GISTEMP; T. Smith and NOAA/NCDC for MLASST; D. Dewitt and the IRI for ECHAM4.5 and ECHAM5 data; S. Schubert, P. Pegion, and NASA/GMAO for NSIPP data; M. Alexander, C. Deser, A. Phillips, G. Meehl, and the CCSM Climate Variability Working Group for CAM3 data; J. Kinter and the Center for Ocean-Land-Atmosphere Studies for COLA data; and N.C. Lau, J. Ploshay, and NOAA/GFDL for AM2 data. We thank M. Wallace for thoughtful comments. We also thank two reviewers and the editor E. Schneider for suggestions which improved an earlier version of this manuscript. This work was supported by the NOAA Climate Program Office. 


\section{References}

Anderson JL et al (2004) The new GFDL global atmosphere and land model AM2-LM2: Evaluation with prescribed SST simulations. J Clim 17:4641-4673. doi : 10.1175/1520-0442(2004)017<4089: IOALMO>2.0.CO;2

Barsugli JJ, Sardeshmukh PD (2002) Global atmospheric sensitivity to tropical SST anomalies throughout the Indo-Pacific basin J Clim 15:3427-3442. doi : 10.1175/1520-0442(2002)01513427:GASTTS[2.0.CO;2

Barsugli JJ, Shin S-I, Sardeshmukh PD (2006) Sensitivity of global warming to the pattern of tropical ocean warming. Clim. Dyn. 27:483-492. doi:10.1007/s00382-006-0143-7

Bony S, Dufresne J-L, Le Treut H, Morcrette J-J, Senior C(2004) On dynamic and thermodynamic components of cloud changes. Clim Dyn 22:71-86. doi: 10.1007/s00382-003-0369-6

Brohan P, Kennedy JJ, Harris I, Tett SFB, Jones PD (2006) Uncertainty estimates in regional and global observed temperature changes: A new data set from 1850. J Geophys Res 111:D12106. doi:10.1029/2005JD00654

Cash BA, Schneider EK, Bengtsson L (2005) Origin of regional climate differences: role of boundary conditions and model formulation in two GCMs. Cli Dyn 25:709-723. doi: 10.1007/s00382-005-0069-5

DelSole T (2006) Low-frequency variations of surface temperature in observations and simulations. J Clim 19:4487-4507. doi: 10.1175/JCLI3879.1

Deser C, Phillips AS (2006) Simulation of the 1976/77 climate transition over the North Pacific: Sensitivity to tropical forcing. J Clim 19:6170-6180. doi: 10.1175/JCLI3963.1

Deser C, Phillips AS (2008) Atmospheric circulation trends, 1950-2000: The relative roles of oceanic and atmospheric radiative forcing. J Clim (in press).

Dai A (2006) Recent climatology, variability, and trends in global surface humidity. J Clim 19:35893606. doi:10.1175/JCLI3816.1

Folland CK, Shukla J, Kinter J, Rodwell MJ (2002) C20C: The Climate of the Twentieth Century Project. CLIVAR Exchanges 7(2):37-39 (Available from the International CLIVAR Project Office, Southampton Oceanography Centre, Empress Dock, Southampton, SO14 3ZH, UK, http://eprints.soton.ac.uk/19305/01/ex24.pdf)

Hansen JE, Ruedy R, Sato M, Imhoff M, Lawrence W, Easterling D, Peterson T, Karl T (2001) A closer look at United States and global surface temperature change. J Geophys Res 106:23947-23963. doi:

10.1029/2001JD000354

Hegerl GC, Zwiers FW, Braconnot P, Gillett NP, Luo Y, Marengo Orsini JA, Nicholls N, Penner JE, Stott PA (2007) Understanding and Attributing Climate Change. In: Climate Change 2007: The Physical Science Basis. Contribution of Working Group I to the Fourth Assessment Report of the 
Intergovernmental Panel on Climate Change [Solomon S, Qin D, Manning M, Chen Z, Marquis M, Averyt KB, Tignor M, Miller HL (eds.)]. Cambridge University Press, Cambridge, United Kingdom and New York, NY, USA, pp 665-745

Held IM, Soden BJ (2000) Water vapor feedback and global warming. Annu Rev Energy

Environ 25:441-475. doi:10.1146/annurev.energy.25.1.441

Hoerling M, Kumar A (2003) The perfect ocean for drought. Science 299:691-694. doi: 10.1126/science. 1079053

Horel JD, Wallace JM (1981) Planetary-scale phenomena associated with the Southern Oscillation. Mon Wea Rev 109: 813-829

Houghton JT, Ding Y, Griggs DJ, Noguer M, van der Linden PJ, Dai X, Maskell K, C. Johnson CA (Eds.) (2001) Climate Change 2001: The Scientific Basis: Contribution of Working Group I to the Third Assessment Report of the Intergovernmental Panel on Climate Change. Cambridge Univ Press, New York, pp 881

Hurrell JW, Hoerling MP, Philips AS, Xu T (2004) Twentieth century north atlantic climate change. Part I: assessing determinism. Clim Dyn 23:371-389, doi:10.1007/s00382-004-0432-y

Hurrell JW, Hack JJ, Phillips AS, Caron J, Yin J (2006) The dynamical simulation of the Community Atmosphere Model Version 3 (CAM3). J Clim 19:2162-2183

Johns TC et al (2003), Anthropogenic climate change for 1860 to 2100 simulated with HadCM3 model under updated emissions scenarios. Clim Dyn 20:583-612.

Jones PD, Osborn TJ, Briffa KR (1997), Estimating sampling errors in large-scale temperature averages. J Clim 10:2548-2568. doi: 10.1175/1520-0442(1997)010<2548:ESEILS>2.0.CO;2

Kinter JL, Fennessy MJ, Krishnamurthy V, Marx L (2004) An evaluation of the apparent interdecadal shift in the tropical divergent circulation in the NCEP-NCAR reanalysis. J Clim 17:349-361. doi: 10.1175/1520-0442(2004)017\0349:AEOTAI[2.0.CO;2

Knutson TR, Delworth TL, Dixon KW, Held IM, Lu J, Ramaswamy V, Schwarzkopf MD, Stenchikov G, Stouffer RJ (2006), Assessment of Twentieth-century regional surface temperature trends using the GFDL CM2 Coupled Models. J. Clim 19:1624-1651. doi: 10.1175/JCLI3709.1

Lau NC (1997) Interactions between global SST anomalies and the midlatitude atmospheric circulation. Bull Amer. Met. Soc. 78:21-33. doi: 10.1175/1520-0477(1997)078<0021:IBGSAA>2.0.CO;2

Meehl GA, Washington WM, Ammann CM, Arblaster JM, Wigley TML, Tebaldi C (2004) Combinations of natural and anthropogenic forcings in Twentieth-Century climate. J Clim 17:3721-3727. doi :10.1175/1520-0442(2004)017<3721:CONAAF $>2.0 . C O ; 2$ 
Meehl GA et al (2006) Climate change projections for the Twenty-first century and climate change commitment in the CCSM3. J Clim 19:2597-2616. doi: 10.1175/JCLI3746.1

Miyakoda K, Hembree GD, Strickler RF, Shulman I (1972) Cumulative results of extended forecast experiments I: Model performance for winter cases. Mon. Wea. Rev. 100: 836-855. doi : 10.1175/15200493(1972)100<0836:CROEFE >2.3.CO;2

Newman ME (2007) Interannual to decadal predictability of tropical and North Pacific sea surface temperatures. J Clim 20:2333-2356. doi:10.1175/JCLI4165.1

Newman ME, Sardeshmukh PD, Penland C (2008) How important is air-sea coupling in ENSO and MJO evolution? Submitted to J Clim. Manuscript available at http://www.cdc.noaa.gov/people/matt.newman/publications.shtml

Penland C, Sardeshmukh PD (1995) The optimal growth of tropical sea surface temperature anomalies. J Clim 8:1999-2024. doi:10.1175/1520-0442(1995)008<1999:TOGOTS>2.0.CO;2

Pierce DW, Barnett TP, AchutaRao KM, Glecker PJ, Gregory JM, Washington WM (2006) Anthropogenic warming of the oceans: observations and model results. J Clim 19:1873-1900. doi: 10.1175/JCLI3723.1

Rayner NA, Parker DE, Horton EB, Folland CK, Alexander LV, Rowell DP, Kent EC, Kaplan A (2003) Global analyses of sea surface temperature, sea ice, and night marine air temperatures since the late nineteenth century. J Geophys Res 108(D14): 4407, doi:10.1029/2002JD002670

Roeckner E et al (1996) The Atmospheric General Circulation Model ECHAM4: Model Description and simulation of Present-day Climate. Max-Planck Institut fur Meteorologie Rep. 218, Hamburg, Germany, pp 90

Roeckner E et al (2006) Sensitivity of simulated climate to horizontal and vertical resolution in the ECHAM5 Atmosphere Model. J. Clim 19:3771-3791. doi: 10.1175/JCLI3824.1

Rodwell MJ, Rowell DP, Folland CK (1999) Oceanic forcing of the wintertime North Atlantic Oscillation and European climate. Nature 398:320-323. doi: 10.1038/18648

Sardeshmukh PD, Hoskins BJ (1988) The generation of global rotational flow by steady idealized tropical divergence. J Atmos Sci 45:1228 -1251. doi :10.1175/1520-0469(1988)045<1228: TGOGRF>2.0.CO;2

Sardeshmukh PD, Compo GP, Penland C (2000) Changes of probability associated with El Niño. J Clim 13:4268-4286. doi:10.1175/1520-0442(2000)013<4268:COPAWE>2.0.CO;2

Schneider EK, Kirtman BP, Lindzen RS (1999) Tropospheric water vapor and climate sensitivity. J Atmos Sci 56:1649-1658. doi: 10.1175/1520-0469(1999)056<1649:TWVACS $>2.0 . C O ; 2$ 
Schneider EK, Bengtsson L, Hu Z-Z (2003) Forcing of northern hemisphere climate trends. J Atmos Sci 60:1504-1521. doi: 10.1175/1520-0469(2003)060<1504:FONHCT>2.0.CO;2

Schubert SD, Suarez MJ, Pegion PJ, Koster RD, Bacmeister JT (2004a) Causes of long-term drought in the U.S. Great Plains. J Clim 17:485-503. doi :10.1175/1520-

0442(2004)017<0485:COLDIT>2.0.CO;2

Schubert SD, Suarez MJ, Pegion PJ, Koster RD, Bacmeister JT (2004b) On the cause of the 1930s Dust Bowl. Science 303:1855-1859. doi:10.1126/science.1095048

Seager R, Kushnir Y, Herweijer C, Naik N, Velez J (2005) Modeling of tropical forcing of persistent droughts and pluvials over western North America: 1856-2000. J Clim 18:4065-4088. doi: 10.1175/JCLI3522.1

Sexton DMH, Grubb H, Shine KP, Folland CK (2003) Design and analysis of climate model experiments for the efficient estimation of anthropogenic signals. J Clim 16:1320-1336.

Shin S-I, Sardeshmukh PD, Webb RS, Oglesby RJ, Barsugli JJ (2006) Understanding the Mid-Holocene Climate. J Clim 19:2801-2817. doi: 10.1175/JCLI3733.1

Shukla J et al (2000) Dynamical seasonal prediction. Bull Amer Meteor Soc 81:2593-2606. doi :10.1175/1520-0477(2000)081<2593:DSP>2.3.CO;2

Shukla J, DelSole T, Fennessy M, Kinter J, Paolino D (2006) Climate model fidelity and projections of climate change. Geophys Res Lett 33:L07702, doi:10.1029/2005GL025579

Smith TM, Reynolds RW (2005) A global merged land-air-sea surface temperature reconstruction based on historical observations (1880-1997). J Clim 18:2021-2036. doi: 10.1175/JCLI3362.1

Soden BJ, Jackson DL, Ramaswamy V, Schwarzkopf MD, Huang X (2005) The radiative signature of upper tropospheric moistening. Science 310:841-844. doi:10.1126/science.11156

Stott PA, Jones GS, Lowe JA, Thorne P, Durman C, Johns TC, and Thelen J-C (2006) Transient climate simulations with the HadGEM1 climate model: Causes of past warming and future climate change. J Clim 19:2763-2782. doi:10.1175/JCLI3731.1

Sutton RT, Dong B, Gregory JM (2007) Land/sea warming ratio in response to climate change: IPCC AR4 model results and comparison with observations. Geophys Res Let 34:L02701, doi:10.1029/2006GL028164

Thompson CJ, Battisti DS (2001) A linear stochastic dynamical model of ENSO. Part II:Analysis. J Clim 14:445-466. doi :10.1175/1520-0442(2001)014<0445:ALSDMO>2.0.CO;2

Ting M, Sardeshmukh PD (1993) Factors determining the extratropical response to equatorial diabatic heating anomalies. J Atmos Sci 50:907-918. doi : 10.1175/1520- 
0469(1993)050<0907:FDTERT>2.0.CO;2

Zhang D, McPhaden MJ (2006) Decadal variability of the shallow Pacific meridional overturning circulation: Relation to tropical sea surface temperatures in observations and climate change models. Ocean Modelling 15:250-273. doi: 10.1016/j.ocemod.2005.12.005 
Figure 1. (a) Observed and (b,c) simulated recent surface air temperature change shown as the 1991-2006 average minus the 1961-1990 average. (b) Mean change in 24 ECHAM4.5 simulations with prescribed observed SSTs. (c) As in (b) but using 23 NASA/NSIPP simulations. Annual averages were calculated from July to June. Years indicate the June of the average. In all panels, yellows and reds indicate positive values while blues indicate negative values. All panels have been lightly smoothed to total spherical wavenumber 17 to emphasize regional features.

Figure 2. Simulated ensemble mean changes as in Fig. 1c using the NASA/NSIPP simulations. (a) Percent change in ensemble-mean $300 \mathrm{hPa}$ specific humidity. (b) Change in ensemble-mean $300 \mathrm{hPa}$ air temperature (c) Change in the $500 \mathrm{hPa}$ pressure vertical velocity. Negative values indicate enhanced upward motion. (d) Change in the $300 \mathrm{hPa}$ relative humidity. Coloring and smoothing are as in Fig. 1.

Figure 3. Simulated ensemble mean changes as in Fig. 1c using the NASA/NSIPP simulations. (a) Change in the downward surface longwave radiative flux. (b) Change in the absorbed surface shortwave radiative flux. (c) Change in the upward surface longwave radiative flux. (d) Change in the turbulent (sensible plus latent) surface heat flux. Coloring and smoothing are as in Fig. 1.

Figure 4. Simulated ensemble mean change in horizontal temperature advection in the $1000 \mathrm{hPa}$ to $850 \mathrm{hPa}$ layer. Coloring and smoothing are as in Fig. 1.

Figure 5. Simulated mean change in surface temperature, comparing runs with prescribed SSTs to those with additional prescribed natural and anthropogenic forcings. (a,c) as in Fig. 1c using (a) the 14 NASA/NSIPP lowresolution simulations with prescribed observed SSTs and (c) the 8 simulations forced additionally with timevarying $\mathrm{CO}_{2}$. (b,d) Mean change in the 1991-2000 average minus the 1961-1990 average using 10 NCAR/CAM3 simulations with prescribed (b) observed SSTs and sea ice, and (d) additional anthropogenic and natural forcings. Coloring and smoothing are as in Fig. 1. 
Table 1. Description of the Atmospheric General Circulation Model (AGCM) simulations used in this study. All simulations were generated with prescribed observed monthly sea surface temperature variations and different initial conditions over the indicated period. Additional forcings were prescribed in some simulations. Columns show the name of the model used, the number of ensemble members $N$, the horizontal grid discretization method and approximate latitude-longitude spacing, the number of vertical levels, the reference publication for the ensemble, and the name of the modeling center that generated the ensemble.

\begin{tabular}{|c|c|c|c|c|c|}
\hline $1961-2006$ & & & & & \\
\hline Model & $\mathrm{N}$ & $\begin{array}{l}\text { Horizontal grid } \\
\text { discretization }\end{array}$ & $\begin{array}{l}\text { Vertical } \\
\text { Levels }\end{array}$ & Reference & Center \\
\hline European ECHAM4.5 & 24 & Spectral T42 $\left(\sim 2.8^{\circ}\right)$ & 18 & Roeckner et al. (1996) & $\begin{array}{r}\text { International } \\
\text { Research Institute } \\
\text { (IRI) }\end{array}$ \\
\hline \multirow{2}{*}{$\begin{array}{l}\text { NASA Seasonal to } \\
\text { Interannual Prediction } \\
\text { Project (NSIPP) }\end{array}$} & $9^{1}$ & Gridpoint $\left(2^{\circ} \times 2.5^{\circ}\right)$ & 34 & Schubert et al. (2004a) & \multirow{2}{*}{$\begin{array}{r}\text { Global Modeling } \\
\text { and Assimilation } \\
\text { Office (GMAO) }\end{array}$} \\
\hline & 14 & Gridpoint $\left(3^{\circ}\right.$ X $\left.3.75^{\circ}\right)$ & 34 & Schubert et al. (2004b) & \\
\hline NSIPP $\mathrm{CO}_{2}$ & $8^{2}$ & Gridpoint $\left(3^{\circ} \times 3.75^{\circ}\right)$ & 34 & Schubert et al. (2004b) & GMAO \\
\hline \multicolumn{6}{|l|}{ 1991-2000 } \\
\hline $\begin{array}{l}\text { Center for Ocean-Land- } \\
\text { Atmosphere (COLA) model } \\
\text { version } 2.2\end{array}$ & $10^{1}$ & Spectral T63 $\left(\sim 1.875^{\circ}\right)$ & 18 & Kinter et al. (2004) & COLA \\
\hline European ECHAM5 & 24 & Spectral T42 $\left(\sim 2.8^{\circ}\right)$ & 19 & Roeckner et al. (2006) & IRI \\
\hline $\begin{array}{l}\text { Geophysical Fluid } \\
\text { Dynamics Laboratory } \\
\text { (GFDL) AM2 }\end{array}$ & $10^{1}$ & Gridpoint $\left(2^{\circ}\right.$ X $\left.2.5^{\circ}\right)$ & 24 & Anderson et al. (2004) & GFDL \\
\hline \multirow{2}{*}{$\begin{array}{l}\text { National Center for } \\
\text { Atmospheric Research } \\
\text { Community Atmospheric } \\
\text { Model } 3 \text { (NCAR/CAM3) }\end{array}$} & $5^{1}$ & Spectral T42 $\left(\sim 2.8^{\circ}\right)$ & \multirow{2}{*}{26} & \multirow{2}{*}{ Hurrell et al. (2006) } & \multirow{2}{*}{ NCAR } \\
\hline & $5^{1}$ & Spectral T85 $\left(\sim 1.4^{\circ}\right)$ & & & \\
\hline \multirow{2}{*}{ NCAR/CAM3 (IPCC) } & $5^{1,3}$ & Spectral T42 $\left(\sim 2.8^{\circ}\right)$ & \multirow{2}{*}{26} & \multirow{2}{*}{ Deser and Phillips(2008) } & \multirow{2}{*}{ NCAR } \\
\hline & $5^{1,3}$ & Spectral T85 $\left(\sim 1.4^{\circ}\right)$ & & & \\
\hline
\end{tabular}

${ }^{1}$ Sea ice concentration was also prescribed.

${ }^{2} \mathrm{CO}_{2}$ variations as in Johns et al. (2003) were also prescribed.

${ }^{3}$ Anthropogenic and natural radiative forcings were also prescribed. These included time-varying solar irradiance and volcanic aerosols, as well as anthropogenic sulfate aerosols, tropospheric and stratospheric ozone, well-mixed GHGs $\left(\mathrm{CO}_{2}, \mathrm{CH}_{4}, \mathrm{~N}_{2} \mathrm{O}\right)$, halocarbons, and black carbon aerosols (Meehl et al. 2006). These forcings are the same as in the NCAR Community Climate System Model 3 Twentieth Century simulations assessed in the IPCC's Fourth Assessment Report (Hegerl et al. 2007). 
Table 2. Comparison of observed and simulated continental near surface temperature change relative to 1961-1990. $N$ is the number of ensemble members. Correlation shows the area-weighted pattern correlation (e.g., Miyakoda et al. 1972) between the observed and simulated temperature change fields. Bias is the area-weighted average difference between the simulated and observed continental fields. The observed global continental average anomaly is 0.48 C for 1991-2006 and 0.38 C for 1991-2000. The Percentage Larger is the continental areal coverage of simulated local temperature changes that are larger than observed. An asterisk $(*)$ indicates that the statistic is significant at or above the $5 \%$ level assuming 8 spatial degrees of freedom.

$\underline{1991-2006}$

$\begin{array}{lrlll}\text { European ECHAM4.5 } & 24 & 0.74 * & -0.05 & 47 \% \\ \text { NASA/NSIPP } & 23 & 0.79^{*} & -0.07 & 41 \% \\ \text { NASA/NSIPP with } \mathrm{CO}_{2} & 8 & 0.76^{*} & -0.08 & 38 \%\end{array}$

$\underline{1991-2000}$

European ECHAM4.5

NASA/NSIPP

NASA/NSIPP with $\mathrm{CO}_{2}$

COLA v2.2

European ECHAM5

GFDL/AM2

NCAR/CAM3

NCAR/CAM3 (IPCC)
24

23

8

10

24

10

10

10
Correlation

Bias

Percentage Larger than Observed

.


Most Recent Surface Temperature Change (1991-2006 minus 1961-1990)

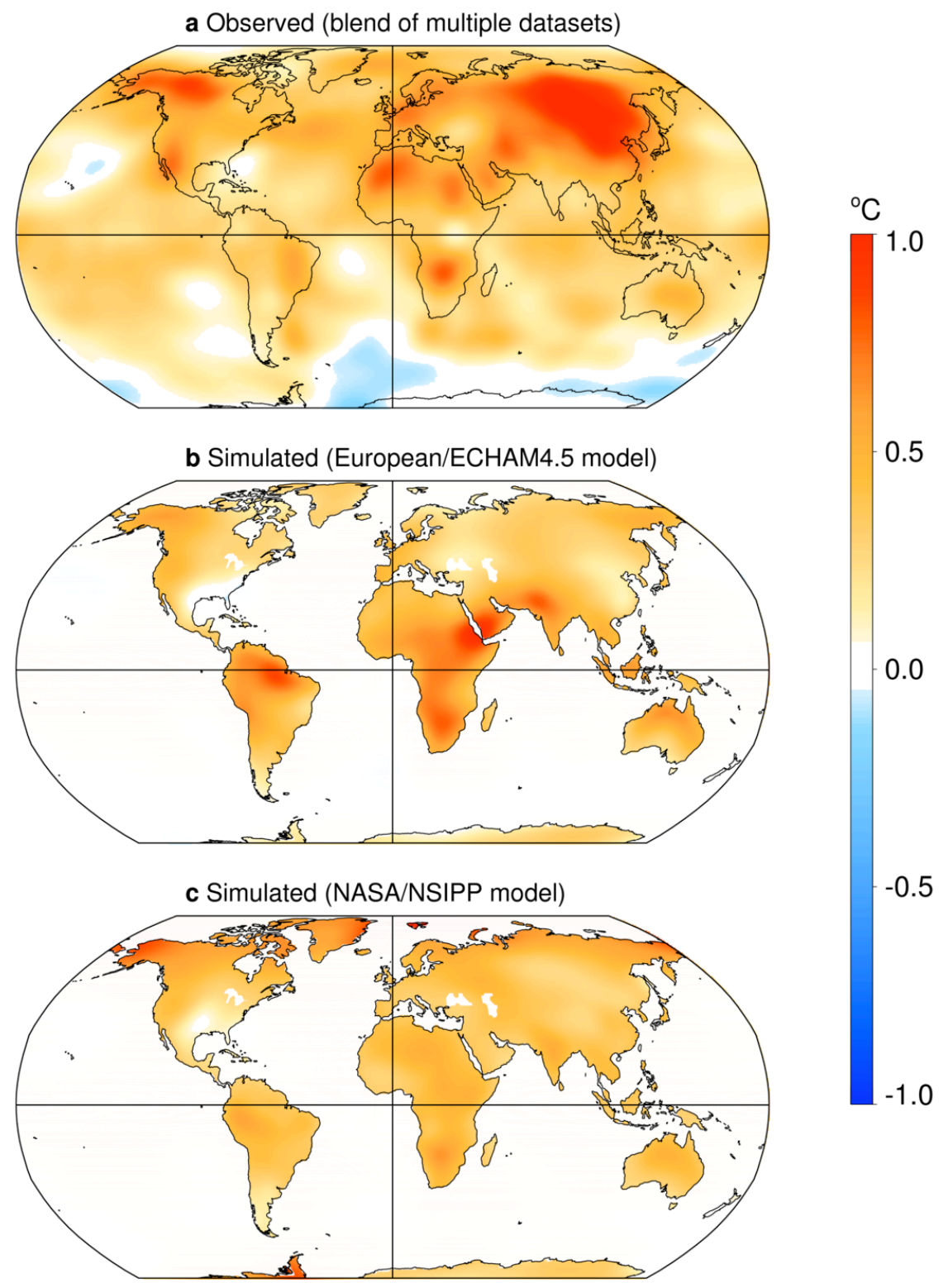

Figure 1. (a) Observed and (b,c) simulated recent surface air temperature change shown as the 1991-2006 average minus the 1961-1990 average. (b) Mean change in 24 ECHAM4.5 simulations with prescribed observed SSTs. (c) As in (b) but using 23 NASA/NSIPP simulations. Annual averages were calculated from July to June. Years indicate the June of the average. In all panels, yellows and reds indicate positive values while blues indicate negative values. All panels have been lightly smoothed to total spherical wavenumber 17 to emphasize regional features. 

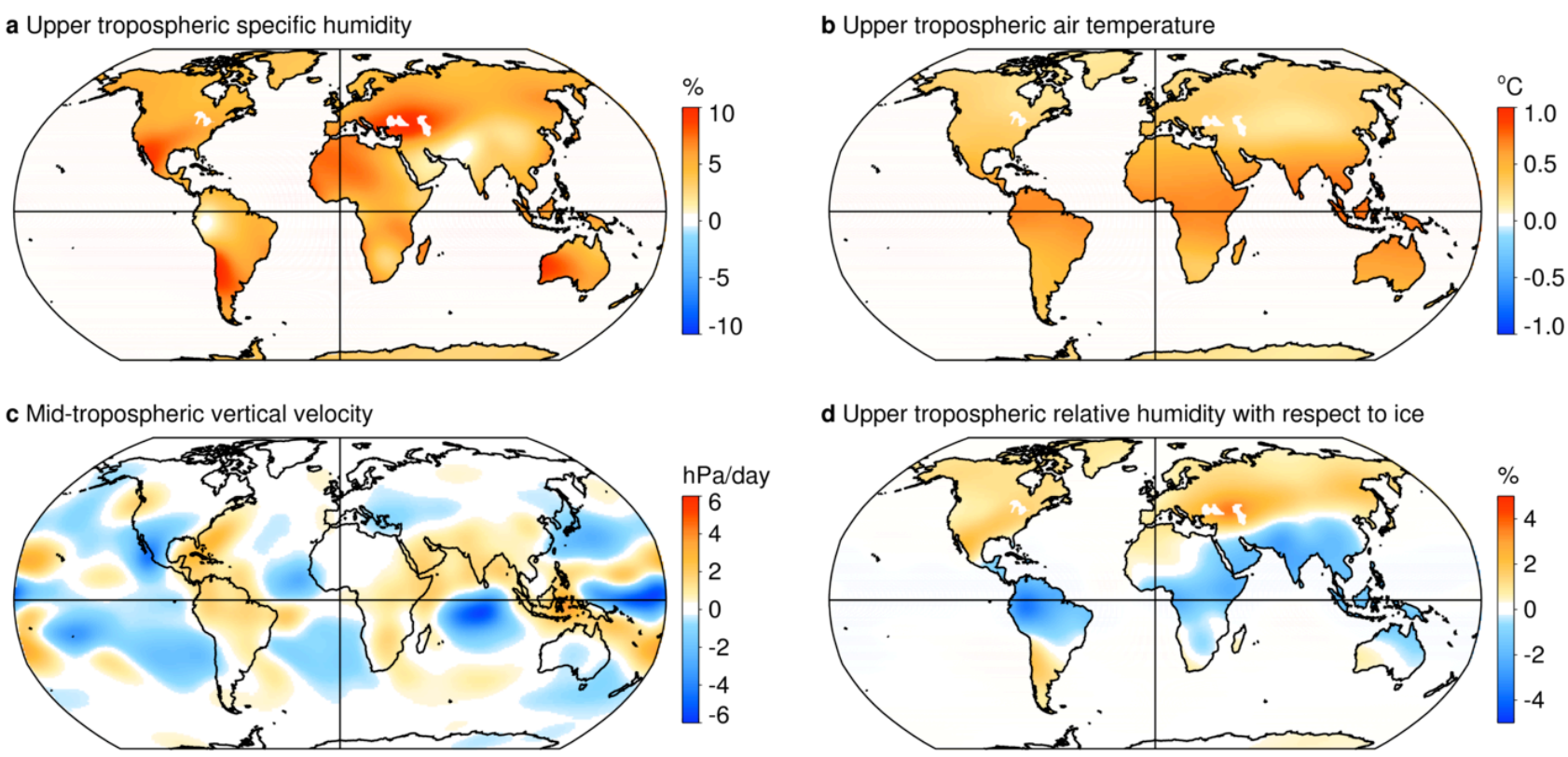

Figure 2. Simulated ensemble mean changes as in Fig. 1c using the NASA/NSIPP simulations. (a) Percent change in ensemble-mean $300 \mathrm{hPa}$ specific humidity. (b) Change in ensemble-mean $300 \mathrm{hPa}$ air temperature (c) Change in the $500 \mathrm{hPa}$ pressure vertical velocity. Negative values indicate enhanced upward motion. (d) Change in the $300 \mathrm{hPa}$ relative humidity. Coloring and smoothing are as in Fig. 1. 

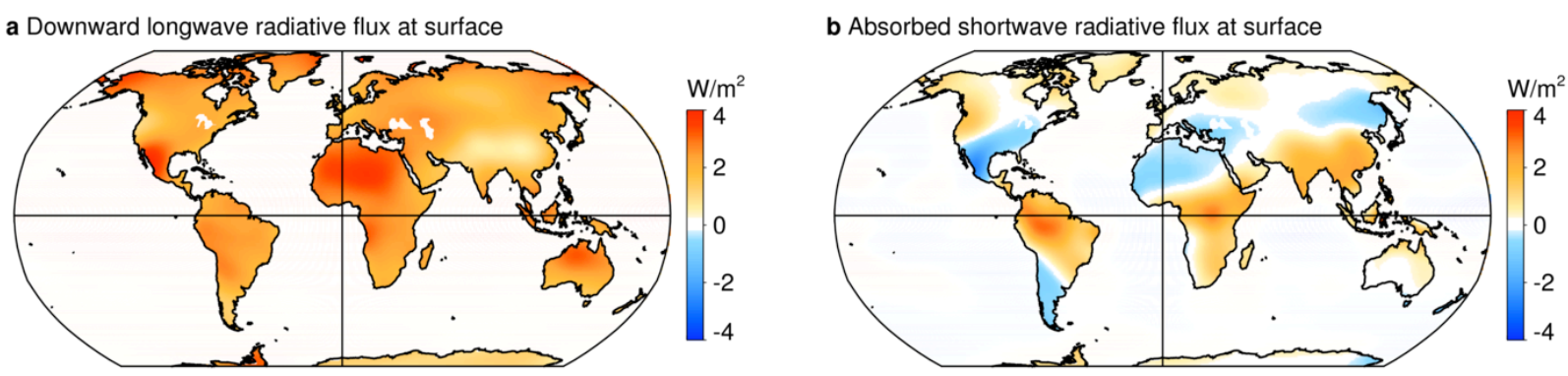

c upwelling_longwave_flux_at_surface
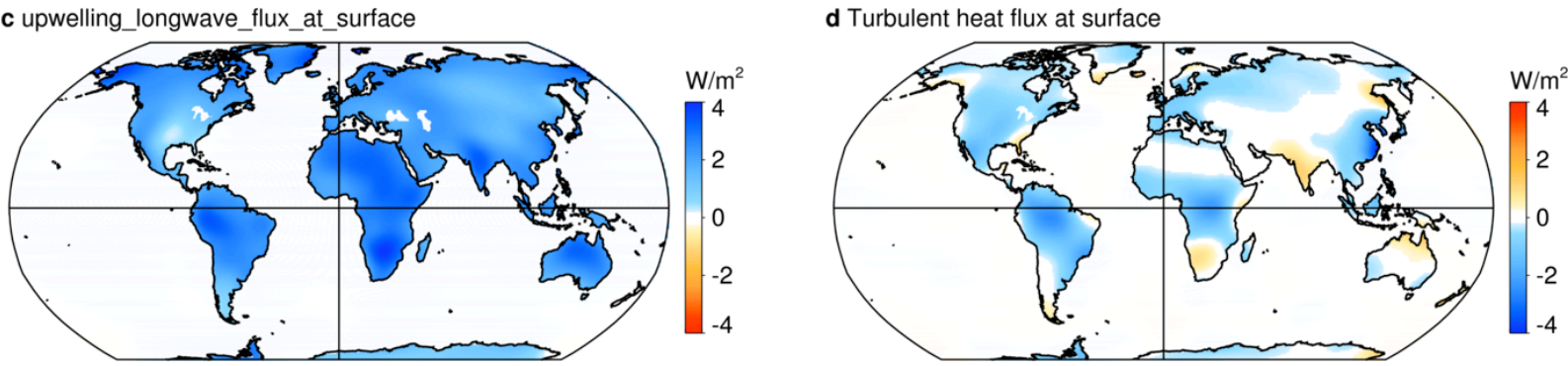

Figure 3. Simulated ensemble mean changes as in Fig. 1c using the NASA/NSIPP simulations. (a) Change in the downward surface longwave radiative flux. (b) Change in the absorbed surface shortwave radiative flux. (c) Change in the upward surface longwave radiative flux. (d) Change in the turbulent (sensible plus latent) surface heat flux. Coloring and smoothing are as in Fig. 1. 


\section{Simulated change in lower tropospheric horizontal temperature advection (1991-2006 minus 1961-1990)}

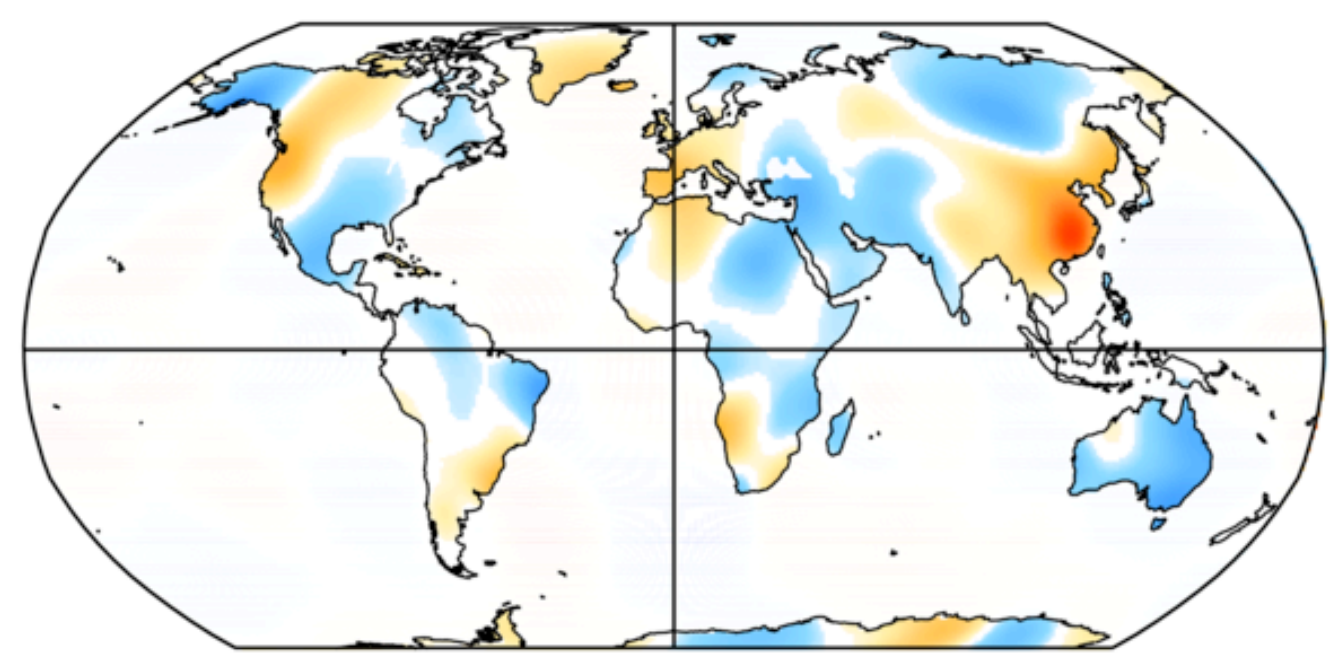

K/day

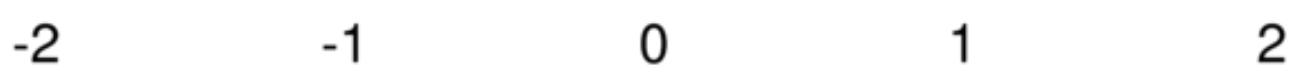

Figure 4. Simulated ensemble mean change in horizontal temperature advection in the $1000 \mathrm{hPa}$ to $850 \mathrm{hPa}$ layer. Coloring and smoothing are as in Fig. 1. 


\section{Simulated Surface Temperature Change}

1991-2006 minus 1961-1990 (NASA/NSIPP model)

a Forced with observed SST changes

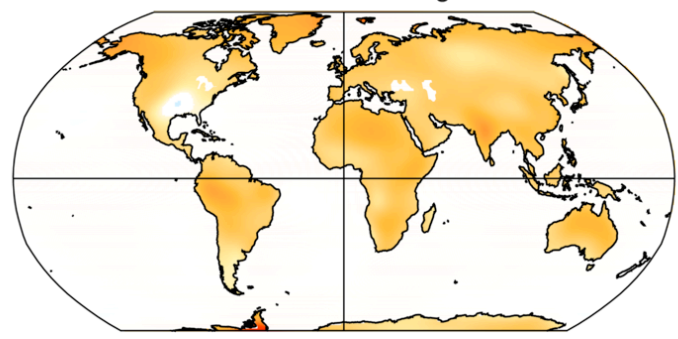

c Forced with observed SST and $\mathrm{CO}_{2}$ changes

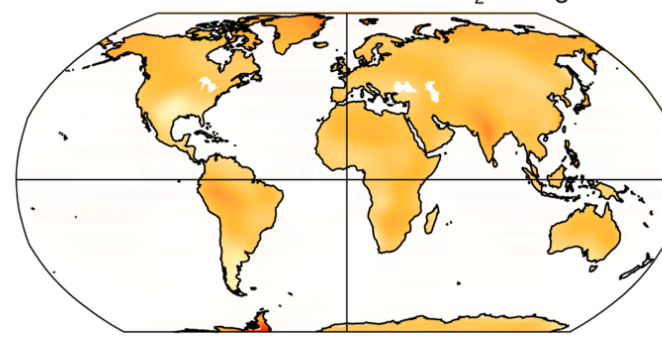

${ }^{\circ} \mathrm{C}$
1991-2000 minus 1961-1990 (NCAR/CAM3 model)

b Forced with observed SST and Sea Ice changes

1.0

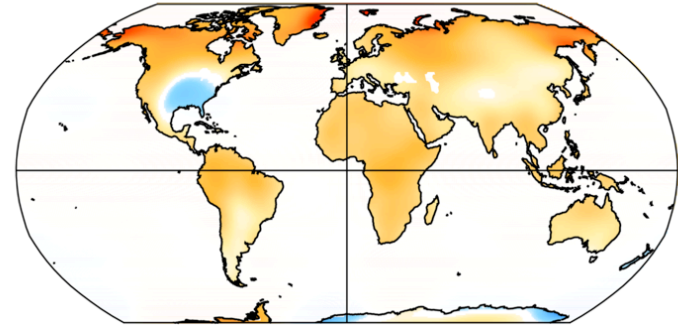

${ }^{\circ} \mathrm{C}$ 1.0

0.5

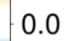

d Forced with observed SST, $\mathrm{CO}_{2}$, and other forcings

0.0

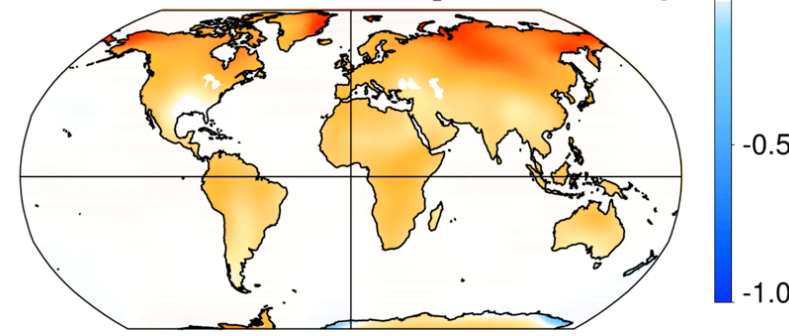

Figure 5. Simulated mean change in surface temperature, comparing runs with prescribed SSTs to those with additional prescribed natural and anthropogenic forcings. (a,c) as in Fig. 1c using (a) the 14 NASA/NSIPP lowresolution simulations with prescribed observed SSTs and (c) the 8 simulations forced additionally with timevarying $\mathrm{CO}_{2}$. (b,d) Mean change in the 1991-2000 average minus the 1961-1990 average using 10 NCAR/CAM3 simulations with prescribed (b) observed SSTs and sea ice, and (d) additional anthropogenic and natural forcings. Coloring and smoothing are as in Fig. 1. 